\title{
The Potential of Silane Coated Calcium Carbonate on Mechanical Properties of Rigid PVC Composites for Pipe Manufacturing
}

\author{
Amin Al Robaidi ${ }^{1}$, Ahmad Mousa ${ }^{1}$, Sami Massadeh ${ }^{1}$, Ibrahim Al Rawabdeh ${ }^{2}$, Nabil Anagreh ${ }^{1}$ \\ ${ }^{1}$ Materials Department, Al-Balq'a Applied University, Salt, Jordan; ${ }^{2}$ Industrial Engineering Department, University of Jordan, Am- \\ man, Jordan. \\ Email:mousa@rocketmail.com
}

Received July $7^{\text {th }}, 2010$; revised November $3^{\text {rd }} 2010$; accepted May $12^{\text {th }}, 2011$.

\begin{abstract}
The inclusion of $\mathrm{CaCO}_{3}$ and kaolin in polyvinyl chloride (PVC) polymer matrices greatly enhances the physical and mechanical properties of the composite. In this study, the effects of kaolin and surface treatment of $\mathrm{CaCO}_{3}$ and kaolin particles on the microstructure and mechanical properties of PVC composites filled with kaolin particles via melt blending method were studied by means of SEM, tensile, Charpy impact testing. Treated and untreated kaolin particles were dispersed in matrices of PVC resin at different concentrations up to $30 w t$ percentage. The tensile strength, elastic modulus, strain to failure and morphology of the resulting composites were measured for various filler loadings. Uniform dispersion of the fillers into the matrix proved to be a critical factor. SEM images revealed that small sized particles were more agglomerated than micron-sized particles and the amount of agglomerates increased with increasing particle content. Silane treated Kaolin-CaCO $3 / P V C$ composites had superior tensile and impact strengths to untreated kaolin-CaCO$/ 2$ PV composites. The Young's modulus of all composites increased with increasing particle content up to maximum at $10 \%$ filler loading followed by gradually decreasing as content increased.
\end{abstract}

Keywords: Polyvinyl Chloride)/Calcium Carbonate (PVC/) Nano-Composite, Particle Size, Melt Blending, Tensile Testing, Charpy Impact

\section{Introduction}

Kaolin and calcium carbonate has long been recognized as useful additives for thermoplastics and particularly in PVC for many applications. Ground kaolin and calcium carbonate are generally used as filler with an interesting ratio performance/price. The specific structure allows this material to fulfill additional functions like Processing aid, impact modification and better weather ability. Its regular and controlled crystalline shape and ultra fine particle size together with the hydrophobic surface coating combine to the benefit of both polymer processing and subsequent physical properties. PVC is the second most consumed polymer right after PE. This low-cost material has numerous advantages, such as a high modulus, excellent chemical resistance and easy conversion. The addition of low-cost fillers such as calcium carbonate or talc was historically justified by the cost reduction; however, performance improvements and other benefits brought by the use of these materials are the cause of its increasing use in
PVC systems [1-5]. The major challenge in plastic reinforcement is to reach an optimal balance between Young Modulus and Impact resistance [6-9]. The most favorable balance could be obtained by a good control of dispersion and adhesion between the filler and polymer matrix as shown in Figure 1. Increasing filler percentages after exceeding a certain concentration will significantly affects impact resistance and modulus of elasticity $[4,9]$. Therefore treating of the filler to achieve a better dispersion and increase filler matrix compatibility is targeted. Silane is a material of choice due to its ability to form grafting species with the polymer matrix and its availability as a commercial product.

\section{Experimental}

Sample Preparation:

Different PVC samples were prepared using brabender plastograh. Batches were produced by the addition of one pack stabilizer system in the mixing station followed by 


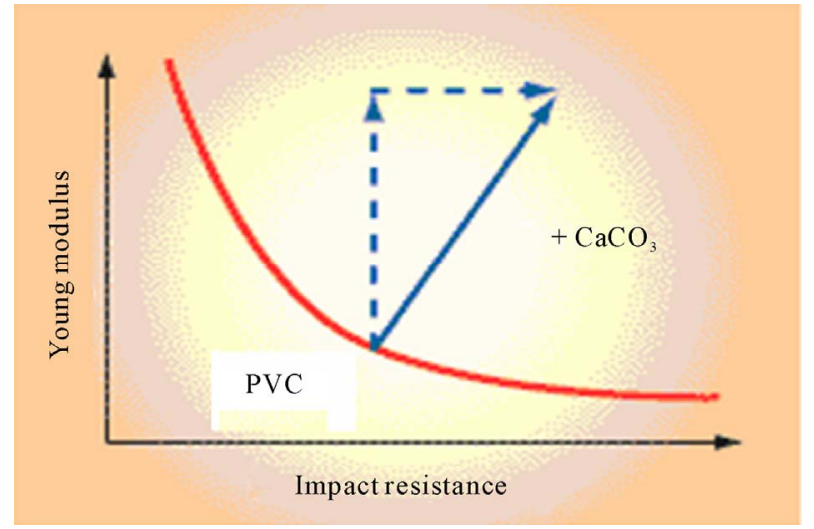

Figure 1. Balanced conditions in PVC systems between Charpy Impact and Young modulus (schematic).

adding different percentages of kaoline and $\mathrm{CaCO}_{3}$ untreated and with silane treated, as listed in Table 1 below. One pack stabilizer system manufactured by DSM was used and kept constant by $3 \%$ concentration through out all formulations. During the mixing step torque and fusion time were measured, that reflects rheological behaviour of the compound. Compounding temperature was kept const at $190^{\circ} \mathrm{C}$ for all samples prepared. All ingredients were added to the PVC matrix in accordance to their weight percentage to the Brabender Sigma mixer and were mixed for (4) minutes at $100 \mathrm{rpm}$ and $140^{\circ} \mathrm{C}$, the samples weights were measured using SCALTEC accurate balance. When mixing was completed, $2 \mathrm{~mm}$ thickness sheets were made using a hot press. Tensile samples according to ASTM 3039 were cut from the sheets for mechanical testing. The probes were subjected to mechanical testing using Ektron tensile testing machine and to charpy impact test using a Ciest impact-testing machine. It is will none that particle size has a significant impact on the mechanical properties. Choosing $\mathrm{CaCO}_{3}$ small particle size was selected to reach good mechanical performances. The $\mathrm{CaCO}_{3}$ particle size, commercial grade with an average particle size of 5 micron was used. Kaolin particle size was around $0.2-0.5 \mathrm{mi}-$ crons. Disadvantage of fine particle, is its ability to agglomerate during the manufacturing process. However, to get that total benefit, care must be taken to disperse them correctly in the polymer matrix.

Dispersion quality affects the final agglomerate size in the polymer: an optimal dispersion is one that evenly distributes throughout a polymer down to the smallest units, the aggregates, a poorer dispersion results in larger agglomerates (Figure 2), moreover, affects finally the mechanical properties.

To have improved and more homogenous distribution, the filler particles were treated with silane. Moreover,
Table 1. Formulation prepared in this study.

\begin{tabular}{ccccc}
\hline $\begin{array}{c}\text { PVC } \\
\text { weight } \%\end{array}$ & $\%$ & $\mathrm{CaCO}_{3}$ & $\begin{array}{c}\text { Impact } \\
\text { modifier } \%\end{array}$ & $\begin{array}{c}\text { treated with } \\
\text { silane }\end{array}$ \\
\hline 100 & ref & ref & - & - \\
97 & 3 & 0 & 0 & no \\
97 & 3 & 0 & 0 & yes \\
95 & 5 & 0 & 0 & no \\
95 & 5 & 0 & 0 & yes \\
90 & 10 & 0 & 0 & no \\
90 & 10 & 0 & 0 & yes \\
87 & 10 & 3 & 3 & no \\
80 & 20 & 0 & 0 & yes \\
80 & 20 & 0 & 0 & no \\
77 & 20 & 3 & 3 & no \\
70 & 30 & 0 & 0 & no \\
70 & 30 & 0 & 0 & yes \\
\hline
\end{tabular}

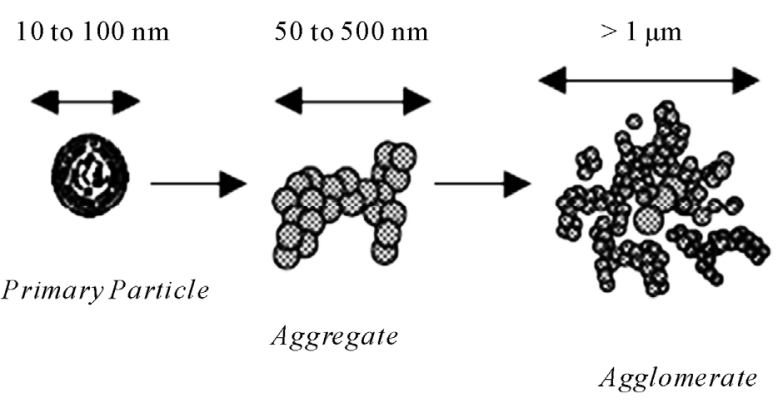

Figure 2. Primary particles fuse together in the reactor and form aggregates and agglomerates.

treating of the particles with silane was aimed to improved compatibility with the PVC matrix. SEM photographs in Figure 3 shows $\mathrm{CaCO}_{3}$ particle agglomeration; when the $\mathrm{CaCO}_{3}$ was treated with silane (Figure 3), a homogenous distribution was achieved. The treatment of the filler was conducted by placing $250 \mathrm{~g}$ in the oven at $90^{\circ} \mathrm{C}$, for 15 minutes, then the addition of silane using micropipette at weight percentages of $2.5 \%$ and letting the mix in the oven at $90^{\circ} \mathrm{C}$, for 30 minutes. Every 5 minutes the mix were taken out from the oven and shacked thoroughly.

\section{Results and Discussion}

\subsection{Mechanical Testing}

Determination of tensile strength, elongation and impact strength are essential in examining the materials behavior 

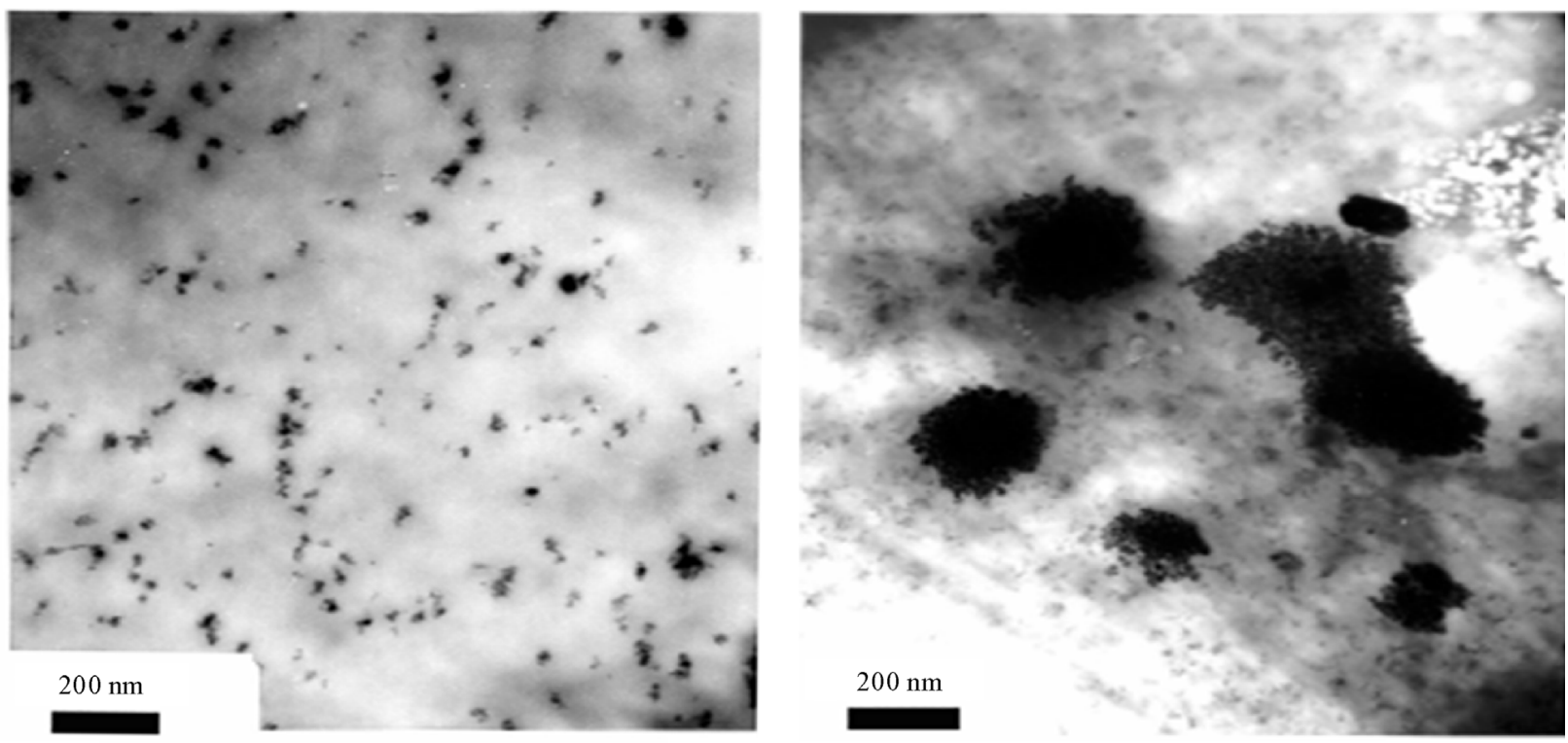

Figure 3. Show the distribution after $\mathrm{CaCO}_{3}$ was treated with silane and particle agglomeration before silane treating.

under engineering conditions. As indicated in Figure 4 below, the Impact strength did increase significantly with $\mathrm{CaCO}_{3}$ content up to approximately $10 \%$, followed be a sharp decrease of Impact resistance. It should be noticed that because of influence of filler effect, impact strength did increase slightly, but there was a considerable decrease of elongation at break. The explanation of this positive behaviour can be found in both the processing improvements that synthetic calcium carbonate provides along with its ability to improve the dispersibility of other components of the formulation i.e. organic impact modifiers.UTS and elongation changed as the percentages of calcium carbonate changes as well. That change was negligible for UTS but more severe in elongation as it could bee seen in Figures 5 and 6 .

\subsection{Rheological Behaviour of Dispersion}

Fusion test were carried out using Brabender plastograph. Some results are shown in the plots below. The degree of

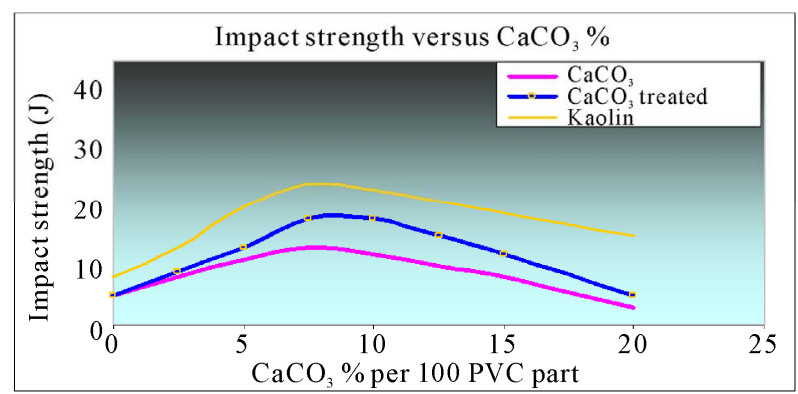

Figure 4. Impact strength versus Calcium Carbonate for rigid PVC designated for electrical pipe extrusion. gelation is a measure of the breakdown of the PVC grain structure and its transformation into a homogenous matrix. If the PVC is under gelled or over gelled, poor physical properties will result. Kaolin and $\mathrm{CaCO}_{3}$, because of its very small particle size and surface coating generates fast, efficient fusion in PVC formulations. The

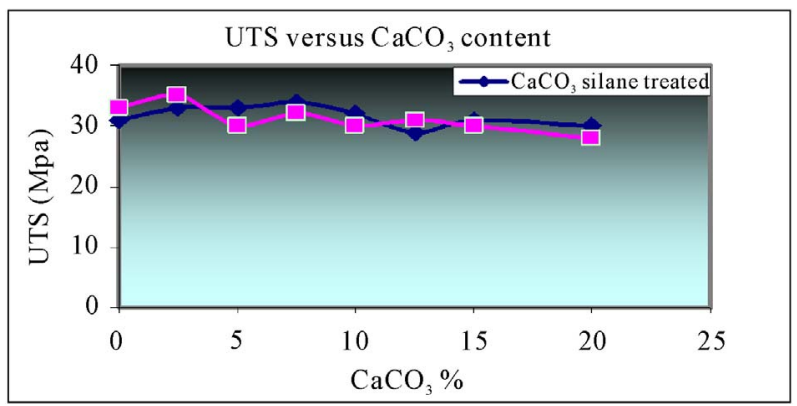

Figure 5. Ultimate Tensile Strength versus content for rigid PVC designated for electrical pipe extrusion.

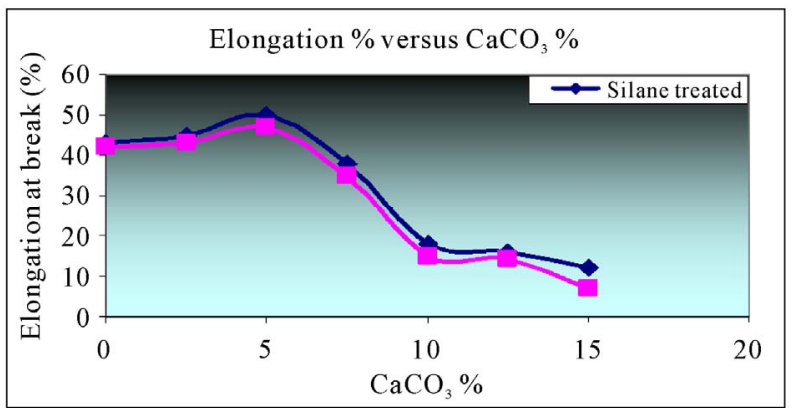

Figure 6. Elongation at break versus content for rigid PVC designated for electrical pipe extrusion. 
more complete gelation that results from the inclusion of calcium carbonate provides a matrix that in comparison to natural PVC has fewer defect sites and opportunities for a crack propagation process leading to reduced mechanical properties.

The fusion time measured for untreated samples was around 24 minutes (Figure 7), whereby a 36 minutes fusion time for the silane treated samples as shown in Figure 8, showing different rheological behaviour, was obtained. Increasing fusion time indicates more stabile compounds. This is an indication for more stable compound and longer resident time in polymer extrusion. Further, it is an indication to obtain ductile failures with reduced impact modifier levels.

\section{Conclusions}

Filler treatment with silane resulted in a better dispersion of the filler particles in PVC matrix and had a good interfacial cohesion. A little amount of particles agglomeration and some cavities were found after treatment, while a lot of agglomeration and cavities occurred when filled with untreated particles. Treated samples had lower equilibrium torque, higher tensile strength and better-notched impact strength. The notched impact strength of tested samples reached $26.5 \mathrm{~kJ} / \mathrm{m}^{-2}$, which was about 4 times as high as that of neat PVC, by $10 / 100$ mass ratio of /PVC. Kaolin particles stiffen and toughen PVC simultaneously, and optimal properties were achieved at

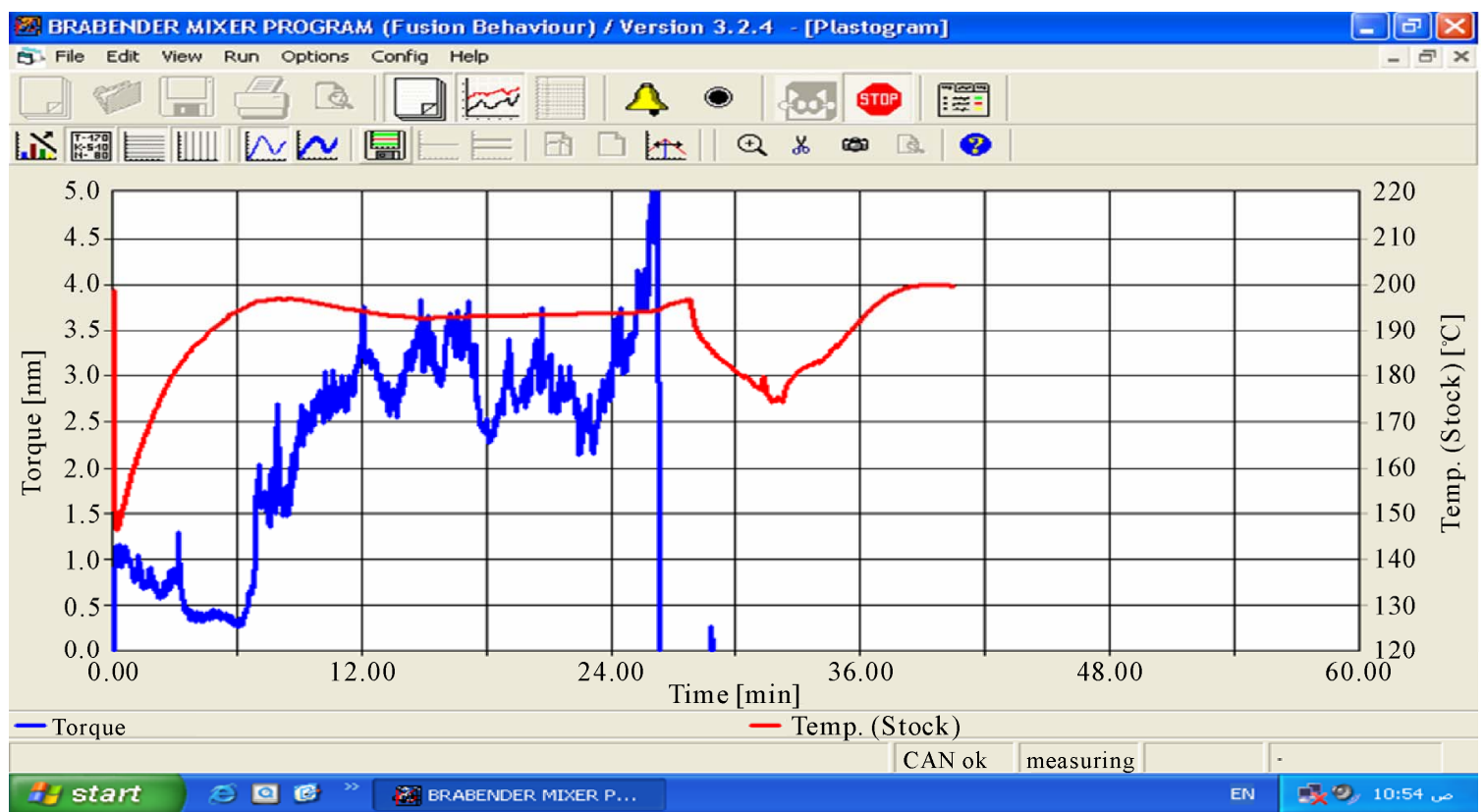

Figure 7. Fusion time of $10 \%$ content for rigid PVC designated for electrical pipe extrusion.

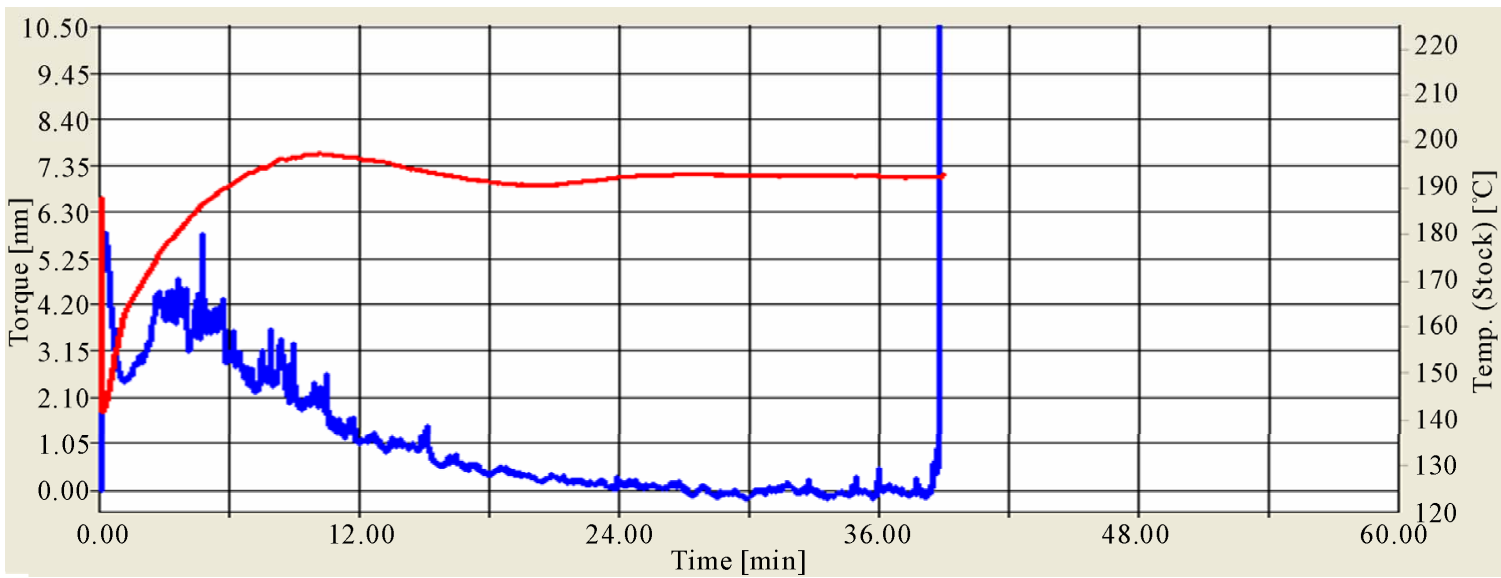

Figure 8. Fusion time of silane coated 15\% content for rigid PVC designated for electrical pipe extrusion. 
$10-\mathrm{wt} \%$ of $\mathrm{CaCO}_{3}$ particles in Young's modulus, tensile yield strength, elongation at break and Charpy notched impact energy. Detailed examinations of micro-failure micro mechanisms of impact and tensile specimens showed that the $\mathrm{CaCO}_{3}$ particles acted as stress raisers leading to debonding/voiding and deformation of the matrix material around the particles. These mechanisms also lead to impact toughening of the composites.

The tensile and impact strengths of $\mathrm{CaCO}_{3} / \mathrm{PVC}$ greatly increased with decreasing $\mathrm{CaCO}_{3}$ particle size, which was attributed to increased interfacial contact area and enhanced interfacial adhesion between filler particles and PVC matrix. Silane kaolin- $\mathrm{CaCO}_{3} / \mathrm{PVC}$ composites had superior tensile and impact strengths to untreated ones.

\section{REFERENCES}

[1] G. A. Ari and I. Aydin, "Nanocomposites Prepared by Solution Blending: Microstructure and Mechanical Properties," Journal of Macromolecular Science, Physics Part B, Vol. 47, No. 2, 2008, pp. 260-267.

[2] S. Sun and C. Li, "Interfacial Structures and Mechanical Properties of PVC Composites Reinforced by $\mathrm{CaCO}_{3}$ with Different Particle Sizes and Surface Treatments," Polymer International, Vol. 55, No. 2, 2006, pp. 158-164. doi:10.1002/pi.1932
[3] R. Krishnamoorti and R. A. Vaia, "Polymer Nanocomposites," Journal of Polymer Science Part B, Vol. 45, 2007, pp. 3252-3259. doi:10.1002/polb.21319

[4] R. C. Advincula, "Encyclopedia of Polymer Science and Technology," John Wiley \& Sons, Hoboken, Vol. 11, 2004, pp. 114-134.

[5] Y. Tsujii, K. Ohno, S. Yamamoto, A. Goto and T. Fukuda, "Structure and Properties of High-Density Polymer Brushes Prepared by Surface-Initiated Living Radical Polymerization," Advances in Polymer Science, Vol. 197, 2006, pp. 1-45.

[6] M. R. Buchmeiser, "Surface-Initiated Polymerization," Advances in Polymer Science, Vol. 197, 2006, pp. 137171.

[7] B. Radhakrishnan, R. Ranjan and W. J. Brittain, "Surface Initiated Polymerizations from Silica Nanoparticles," Soft Matter, Vol. 2, 2006, pp. 386-396. doi:10.1039/b516508c

[8] A. Al-Irobaidi and N. A. Halim, "Correlation between Rheology; Processing and Microstructure in Polymers," Dirasat, Vol. 27, No. 2, 2000.

[9] N. Khreische and A. Al-Irobaidi, "Micro Structure of Weathered Green House PE-Plastic Films," Journal of Polymer Degradation and Stability, Vol. 32, 1991, pp. 105-114. 